streaking on a medium of composition similar to that of the perfusate. Various fungi and bacteria appeared on the plates, particularly on the mannitol plates ; on individual transfer to now medium in an atmosphere free from ammonia all failed to grow, with the exception of two yeasts from the mannitol perfusate, which grew slowly but steadily. These two yeasts, one (non-sporing) resembling a Saccharomyces and one a pink Rhodotorula, were inoculated into nitrogenfree mannitol-phosphate liquid medium and periodically aerated with ammonia-free air; growth was steady and after fourteen days a considerable deposit of yeast had formed. Assessment of nitrogen-content by the micro-Kjeldahl method showed a high gain compared with controls, a gain well above the errors of estimation and corresponding to a rate of fixation (on different occasions) of up to $4 \mathrm{mgm}$. nitrogen per gm. of mannitol originally available. An interesting feature of these nitrogen-starved yeasts was the presence of large oil globules in the cells and a very sparse retention of dye when stained by Gram's method.

In the course of further extensive investigations by Chayen, using perfusion enrichment followed by isolation on nitrogen-free media, a large number of yeasts have been isolated from the $A 1$ horizon of the same Calluna heath soil. A representative sample of these was tested for ability to grow in aerated nitrogen-free media under conditions ensuring the rigid exclusion of atmospheric ammonia; some twenty isolates grew under these conditions. Tests for increase in fixed nitrogen by micro-Kjeldahl estimation on the whole culture gave significant gains; for one Rhodotorula these gains corresponded to the fixation of 1-3 mgm. of atmospheric nitrogen per gm. of glucose available. Further tests on this Rhodotorula and on another isolate, using an isotopic nitrogen technique, are described in the following communication by Roberts and Wilson.

In addition to the nitrogen-fixing yeasts, two quite distinct strains of nitrogen-fixing bacteria of the genus Azotobacter have been isolated using mannitol as the perfusate. These bacteria are distinct from previously described 'species' of Azotobacter, including $A$. indicum. This work, with descriptions of the organisms and their growth under differing experimental conditions, will be published in detail elsewhere.

Department of Botany,

George Metcalfe SONJA Chayen

King's College,

University of London,

London, W.C.2.

July 22 .

${ }^{1}$ Starkey, R. L., and De, P. K., Soil Sci., 47, 329 (1939).

A METHOD has been developed in this laboratory whereby the rate-constant of the nitrogen-fixation process is obtained solely from isotope abundance measurements ${ }^{1}$. At the suggestion of Metcalfe and Chayen, we have applied this method to certain soil yeasts isolated by Chayen and have confirmed their observations that these organisms are capable of taking up molecular nitrogen (see preceding communication).

Cultures of two yeasts, Rhodotorula (I) and Saccharomyces (II), were studied; they were thought to have nitrogen-fixing capacities $1 / 10$ and $1 / 50$, respectively, of that of Azotobacter. An atmosphere

consisting of oxygen, argon and nitrogen, the latter containing $32 \cdot 0$ atom per cent excess of nitrogen-15, was circulated through duplicate cultures of the yeasts in a medium free from combined nitrogen. The cells were actively budding immediately prior to the experiment. At the end of four hours, the cells were harvested, subjected to Kjeldahl digestion, and the ammonia produced converted to nitrogen by reaction with sodium hypobromite. The isotope abundance in these samples was determined by means of a mass spectrometer ; the abundance of nitrogen-15 in ordinary air was 0.41 per cent.

\begin{tabular}{|c|c|c|c|c|c|}
\hline \multirow{2}{*}{ Culture } & \multicolumn{3}{|c|}{ Atmosphere } & \multirow{2}{*}{\multicolumn{2}{|c|}{$\begin{array}{l}\text { Percentage nitrogen-15 } \\
\text { in cell nitrogen } \\
\text { (i) }\end{array}$}} \\
\hline & $p_{\mathrm{N}_{2}}$ & $p_{\mathrm{O}_{2}}$ & $p_{\mathrm{A}}$ & & \\
\hline II & $\begin{array}{l}0.17 \\
0.04\end{array}$ & $\begin{array}{l}0.40 \\
0.40\end{array}$ & $\begin{array}{l}0 \cdot 30 \\
0 \cdot 40\end{array}$ & $\begin{array}{l}1.38 \\
0.45\end{array}$ & $\begin{array}{l}1 \cdot 41 \\
0 \cdot 48\end{array}$ \\
\hline
\end{tabular}

These results show clearly that the yeasts, especially I, had taken up molecular nitrogen. Moreover, the extent to which fixation occurred was consistent with expectations based on total nitrogen determinations.

We are indebted to the Royal Society for a grant with which the isotopic nitrogen used in this experiment was purchased, and to Dr. G. A. Meek, who performed the isotope analyses. One of us (T. G. G. W.) is indebted to the Middlesex Education Committee, and to Glaxo, Ltd., for financial assistance.

E. R. RoBERTS

T. G. G. WILSON

Dept. of Inorganic and Physical Chemistry,

Imperial College of Science and Technology, London, S.W.7. July 22.

${ }^{1}$ Pethica, B. A., Winter, E. R. S., and Roberts, E. R., Biochim. et Biophys. Acta, 14, 85 (1954).

\section{Acceleration of Flowering in Non-vernalized Chrysanthemums by the Removal of Apical Sections of the Stem}

Ir has been shown that plants of Chrysanthemum morifolium 'Sunbeam' (incorrectly termed 'Indian Summer'), raised from basal cuttings taken from parent plants grown and flowered at high temperatures, require a period of low temperature or vernalization in order that normal stem elongation and rapid flowering may occur. Without such a period of low temperature these plants grown in high temperature conditions $\left(>60^{\circ} \mathrm{F}\right.$.) fail to elongate normally and are considerably delayed in flowering 1.

If an apical section of the stem is removed, however, the two or three lateral shoots thus induced to develop do not show the rosette habit and diageotropic growth characteristic of the main axis, and flower rapidly (see Fig. 1).

Non-vernalized plants of 'Sunbeam', from cuttings taken on December 30, 1953, were grown at temperatures above $60^{\circ} \mathrm{F}$. in natural day-length conditions until June 15, 1954. On this date the plants, which had laid down approximately fifty leaves, were cut back to twenty-five, thirty-five or forty-five leaves, or left intact, and were placed immediately in shortday (10-hour) conditions. The laterals, which developed as a result of removal of the apical sections, elongated normally and rapidly produced macroscopically visible buds. The main axis of the intact 